\title{
Influences of rurality on action to diagnose cancer by primary care practitioners- results from a Europe-wide survey in $\mathbf{2 0}$ countries
}

\author{
Peter Murchie,1 Wei Lynn Khor,1 Rosalind Adam,1 Magdalena Esteva,2 Emmanouil Smyrnakis,3
}

Davorina Petek,4 Hans Thulesius,5 Peter Vedsted,6 David McLernon,1 Michael Harris.7,8

1. Institute of Applied Health Sciences, University of Aberdeen, Polwarth Building, Foresterhill, Aberdeen, UK, AB25 2ZD

2. Cap Formació Continuada, Majorca Primary Care Department. Unit of research. Balearic Islands Health Research Institute (IdISBa), Preventive Activities and Health Promotion Network (redIAPP), Escola Graduada 3, 07002 Palma Mallorca

3. Laboratory of Primary Health Care, General Practice and Health Services Research - Medical School, Aristotle University of Thessaloniki, Greece

4. Department of Family Medicine, Faculty of Medicine, University of Ljubljana, Poljanski Nasip 58, 1000 Ljubljana

5. Lunds Universitet, Box 117, 22100 LUND

6. Research Unit for General Practice in Aarhus, Denmark, Bartholins Allé 2, Aarhus University, 8000 Aarhus C, Denmark

7. Department for Health, University of Bath, England, UK. BA2 7AY

8. Berner Institut für Hausarztmedizin (BIHAM), University of Bern, Bern, Switzerland

Correspondence to: Professor Peter Murchie (p.murchie@abdn.ac.uk)

Key words: Primary healthcare; Cancer; Rurality; Geography; Health Outcomes, General practice,

Europe

Word count: 2628 words

\section{FUNDING}

The study on how practicing in a rural setting may impact upon primary care practitioners, access to tests, investigative decisions and attitudes to cancer diagnosis has received no external funding.

\section{HIGHLIGHTS}

- Rural cancer patients are repeatedly demonstrated to have poorer cancer outcomes than urban counterparts.

- In this study we report data from 1,779 representative primary care practitioners from across Europe.

- The study finds compelling evidence that, across Europe, rural primary care practitioners have less direct access to cancer investigations.

- However, the study also finds that rural primary care practitioners across Europe do not delay diagnostic action for patients with potential cancer symptoms compared to their urban counterparts.

- Together the results strongly suggest that health service structure and provision, rather than physician behaviour, is a much more likely source of rural cancer inequality. 


\section{ABSTRACT}

\section{Background}

Rural-dwellers have poorer cancer outcomes than urban counterparts, for reasons which are unclear. At healthcare institution level, poorer access to investigations and different clinical decision-making by rural primary healthcare practitioners (PCPs) could be important.

\section{Aim}

To compare access to investigations, attitudes to cancer diagnosis and clinical decision-making between rural and urban PCPs.

\section{Setting}

A vignette-based cross-sectional survey of rural and urban PCPs in 20 European countries.

\section{Methods}

Data on PCPs' decision-making and attitudes to cancer diagnosis were based on clinical scenarios. Comparisons were made using tests of proportion, univariable and multivariable binary logistic regression.

\section{Results}

Of the 1,779 PCPs completing the survey 541 (30.4\%) practiced rurally. Rural PCPs had significantly less direct access to all investigative modalities: ultrasound; endoscopy; $x$-ray and advanced screening (all p<0.001). Rural PCPs were as likely as urban PCPs to take diagnostic action (investigation and/or referral) at the index consultation in all four clinical vignettes ((OR, 95\% $\mathrm{Cl})$ for lung: 0.90, 0.72-1.12; ovarian: 0.95, 0.75-1.19; breast: 0.87, 0.69-1.09; colorectal: 0.98, 0.75-1.30). Rural PCPs were less likely to refer to a specialist at the index consultation for ovarian cancer (OR $0.7195 \% \mathrm{Cl}$ 0.51-0.99). Rural PCPs were significantly more likely to report that their patients faced barriers to accessing specialist care, but practitioners did not report greater difficulties making specialist referral than their urban counterparts

\section{Conclusions}

European rural PCPs report poorer access to investigations but are at least as likely as urban PCPs to investigate or refer patients that might have cancer at the index consultation.

Abstract Word Count: 250 words 


\section{INTRODUCTION}

Rural-dwellers have poorer cancer outcomes compared to city-dwellers but underlying mechanisms are poorly understood.[1]. Poorer rural cancer outcomes are important socially and economically since $24 \%$ of Europeans live rurally.[2] Evidence for poorer rural cancer outcomes has accumulated over thirty years.[3]. A 1990 case-control study found poorer case-survival rates in non-metropolitan South Australians after adjusting for disease stage.[4]. In 2000, a Scottish analysis of 63,976 people diagnosed from 1991-1995 found that increasing distance from cancer centres was associated with poorer survival for prostate and lung cancer.[5] A Scottish study based on 12,339 people diagnosed with common cancers found lower one-year survival among those living more than 60 minutes from a cancer centre.[6] More recently, a study of 737,495 people diagnosed with cancer in England between 2006 and 2010 reported that those living more than 30 minutes from their GP were more likely to have an emergency presentation and less likely to have screen-detected cancer.[7] Studies of a Danish national cohort of 256,662 cancer patients diagnosed between 2005 and 2016 found that increased distance to hospital was associated with longer diagnostic intervals and later stage for harder to diagnose cancers. $[8,9]$

A recent systematic review reported that, of 39 observational studies from seven countries, most showed poorer outcomes for rural patients with cancer.[1] Narrative synthesis of the data suggested that inequities can exist at the levels of: the individual patient (their demographics and behavioural risk factors); healthcare institutions; urban/rural community environments and culture; and at the level of health policy and service organisation.[1] At a healthcare institutions level, rural communities could have fewer and less specialised healthcare practitioners, with more limited access to investigations.[1]

Most Europeans with potential cancer symptoms present first to a primary care practitioner (PCP) whose decision-making and diagnostic actions will influence the subsequent promptness of cancer diagnosis.[10] It seems plausible that geographical setting could influence PCPs' diagnostic decisionmaking when faced with patients who might have cancer. However, we could identify no studies, explicitly comparing attitudes to primary care cancer diagnosis and decision-making intentions between urban and rural PCPs.

The Örenäs Research Group is a is a European group of primary care researchers that studies the primary care factors that relate to cancer survival. A trans-European collaboration that surveyed PCPs in 20 different European countries [11] gathered data from PCPs in rural and urban settings on their access to investigations, attitudes and decision-making around cancer diagnosis in primary care. This gives the opportunity to explore whether these factors differ significantly between rural and urban European PCPs. 


\section{METHODS}

\section{Objectives}

The objectives of this study were to:

1. Compare rural and urban PCPs' direct access to cancer investigations.

2. Compare likelihood that rural or urban PCPs will arrange investigations or referral at the index consultation for patients with potential cancer symptoms.

3. Compare attitudes of rural and urban PCPs to factors associated with cancer diagnosis in primary care.

\section{Design and study setting}

The study used data from a cross-sectional Örenäs Research Group electronic survey of PCPs in 20 European countries.[11]. Development and piloting of the survey has been previously described.[11] The survey comprised four sections, with Section 1 seeking demographic information including respondents' own assessment of their practices' geographical setting (urban, rural, island/remote and mixed). Section 2 sought information about availability of relevant investigations. Section 3 comprised four clinical vignettes describing symptomatic presentation by four patients, one each with symptoms suggestive of lung, colorectal, ovarian and breast cancer, and presented respondents with questions about their management decisions. Section 4 comprised twenty statements seeking respondents' attitudes to health system factors that might affect primary care cancer diagnosis.

\section{Participants}

Subjects were eligible for the survey if they were doctors working mainly in primary care. These doctors included general practitioners and other doctors with specialist training but working in the community and accessible directly by patients without referral.

\section{Recruitment}

An Örenäs Research Group member acted as national lead in each participating country and emailed survey invitations to PCPs in their areas, aiming to recruit at least 50 participants. Local leads with difficulty achieving required sample sizes increased the number of responses by using snowballing, a recognised technique for recruiting hard-to-reach populations in health studies.[12] Consent was implied by agreeing to take part.

\section{Data management}

Data were collected using SurveyMonkey (SurveyMonkey, California, USA). Anonymised data were extracted by $\mathrm{MH}$ and securely transferred to PM to be managed on a secure server at the Institute of 
Applied Health Sciences, University of Aberdeen, UK. PM, RA and WK had access to the data in full compliance with institutional information governance and quality assurance policies.

\section{Data and outcomes}

The following data were extracted from the survey: country of origin; respondents' characteristics (years since graduation, gender); geographical setting of PCP's practice; access to investigations; management decisions based on four clinical vignettes; agreement with 20 statements reflecting attitudes to health service factors affecting primary care cancer diagnosis.[13] For each attitudinal statement 5-point Likert scale responses were combined into three categories: disagree; neither disagree or agree; and agree.

PCPs responding that they worked in an urban, rural or island/remote setting were included. For subsequent analysis, we combined rural and island/remote into a single rural variable. We excluded those practising in a mixed setting and those with missing values. Country of origin was recoded to designate participating countries using the Kringos classification which uses three dimensions to designate the strength of national primary care systems.[14] Access to individual investigations was re-categorized as access to ultrasound, endoscopy, x-ray and advanced scanning. Four composite binary variables, one for each vignette, were produced to indicate if responding PCPs would take diagnostic action (investigate directly, refer for investigation and/or refer to secondary care) following the index consultation in each vignette.

\section{Statistical analysis}

We compared rural versus urban PCPs by personal characteristics, country and Kringos categories using descriptive statistics and the Chi-squared test. We then compared self-reported direct access to investigative modalities (ultrasound, endoscopy, x-ray and advanced scanning), overall intention to take diagnostic action, and intention to refer to secondary care at the index consultation in each clinical vignettes using the Chi-squared test. Unadjusted odds that rural PCPs would take diagnostic action or refer to secondary care at each index consultation were compared to those for urban PCPs, using univariable binary logistic regression. Subsequent multivariable analysis was used to estimate the odds ratios with adjustment for gender, years since graduation, Kringos classification[14] and direct access to relevant investigations. Because the proportions of rural respondents varied between countries a sensitivity analysis adjusted for country rather than Kringos category was conducted.[14] Urban and rural PCPs' level of agreement with 20 attitudinal statements about health service factors were compared using the chi-squared test for trend. To allow for multiple comparisons a simple Bonferroni correction (0.05/number of tests) was used where five or more tests were conducted.[15] 


\section{RESULTS}

The survey was completed by 2,086 PCPs from 20 European countries. 1238 (59.3\%) practiced in an urban setting, $485(23.3 \%)$ in a rural setting, $56(2.7 \%)$ in a remote or island setting, $295(14.1 \%)$ in a mixed setting, with $12(0.6 \%)$ missing values. The sample for this analysis described in Table 1 comprised 1,779 individuals of whom 541 (30.4\%) were considered rural. Rural PCPs were $47.2 \%$ male compared to $34.0 \%$ of urban respondents $(p<0.001)$ and rural PCPs were significantly more likely to be qualified for longer $(p<0.001)$ but no more likely to be qualified in another specialty. After excluding PCPs who stated that their geographical location was 'mixed', the proportion of rural PCPs ranged from $1.8 \%$ of French respondents to $71.4 \%$ of Swiss respondents $(p<0.001)$. Using the Kringos classification urban respondents were significantly more likely to practice in a strong primary care system $(46.4 \%$ versus $39.7 \%,(p<0.001)) .[14]$

Rural PCPs reported significantly less direct access to each of the four investigative modalities (all $\mathrm{p}<0.001$ ) (Table 2). The largest difference was for endoscopy, with 923 (74.6\%) of urban respondents reporting direct access compared to 312 (57.7\%) of rural respondents. (Table 2 ).

The odds of rural PCPs intending diagnostic action (investigation and/or referral) at the index consultation was not significantly different from the odds of urban PCPs intending diagnostic action for any of the four vignettes following adjustments for gender, years since graduation, Kringos classification and direct access to relevant investigations. (Table 3). In sensitivity analysis, adjusting for country rather than Kringos system, there were no significant differences between rural and urban PCPs in intended diagnostic action. (Supplementary table)

The proportion of rural PCPs intending specialist referral at the index consultation, and the odds (unadjusted and adjusted) of specialist referral by rural PCPs did not differ significantly from Urban PCPs for the lung or breast vignettes. A significantly lower proportion of urban PCPs intended to refer in the colorectal vignette $(71.4 \%$ vs $78.9 \%, p<0.001)$ but the odds of referral by rural PCPs were not significantly greater following adjustment (OR 1.30 (95\% Cl 0.97-1.76). Rural PCPs, however, appeared significantly less likely to refer in the ovarian vignette following adjustment (OR 0.71 ( $95 \% \mathrm{Cl} 0.51$ 0.99) (Table 4). In sensitivity analysis, adjusted for country rather than Kringos system, there were no significant differences in referral intentions of rural or urban PCPs. (Supplementary table)

The comparison of PCPs attitudes is shown in Table 5. More Rural PCPs agreed that referrals were welcome and could be made to specialists they knew. More rural PCPs agreed that their patients had 
greater travelling and costs for to see a specialist, but that costs were met by insurance companies. Rural PCPs indicated lower access to fast-track referral pathways but a greater ability for patients to self-refer to specialists. Rural PCPs more often agreed they had more time to think within consultations and were less likely to refer to reduce workload than urban PCPs. There were no important differences between urban and rural PCPs in attitudes to cost versus quality within the healthcare systems.

\section{DISCUSSION}

\section{Main findings}

Rural PCPs were more likely to be male and to have been qualified for longer. They were less likely to have had direct access to all investigative modalities. Rural PCPs were just as likely to intend diagnostic action at the index consultation as urban counterparts and were as likely indicate that they would refer in three of the four clinical vignettes. Rural PCPs perceived easier access to specialist referral and advice and being under less pressure than urban counterparts. Rural PCPs were more likely to agree that their patients had more travel and greater cost to be investigated for potential cancer.

\section{Comparison with other literature}

There is some evidence that PCPs are aware of the characteristics of the health system and their individual practice or clinic context when making diagnostic decisions.[13,16]. However, we found similar diagnostic and referral intentions by rural and urban PCPs in keeping with a New Zealand government report that rural and urban GPs had similar referral rates.[17]. Our data contradicts a previous survey amongst 100 Tasmanian GPs, where rural respondents believed distance from cancer centres influenced patient management and a social survey in 1,603 Norfolk residents partly attributing fewer out-patient attendances by rural-dwellers to the influence of access to GP behaviour. $[18,19]$. Neither study measured actual PCP intentions as we have. While both of these studies were cited as potentially explanatory by a recent large English study reporting delayed cancer diagnosis in rural patients, our data are more current and comprehensive, and downplay differential GP referral practices as a root cause of rural cancer inequality.[7] On the other hand Canadian researchers found inter-provincial variation in direct GP access to investigations for potential cancer, and suggested this could influence GPs' behaviour and the relative speed of patients' diagnostic workup, a possibility we cannot exclude.[20] Rural GPs are also significantly more likely to undertake primary excision of suspicious skin lesions that subsequently prove to be melanoma, a cancer not explored in this study, and which may be influenced by travel-burden and access issues.[21] 


\section{Strengths and limitations}

This study provides the first trans-European evidence on how healthcare institution factors could influence rural cancer outcomes. The study is large and diverse, including responses from 20 European countries, and controlling for the range of international healthcare-service delivery models, including those with strong, medium and weak traditions of primary care.[14] One third of the sample were rural practitioners, close to the proportion of Europe's population living rurally. The data were collected using a robust and carefully developed survey instrument enabling the first meaningful and large-scale comparison of geographical variation in PCPs attitudes and decision-making for patients with symptoms that could be due to cancer.

Respondents were asked to self-designate the geographical location of their practice, as there is no Europe-wide classification of rurality and concepts of rurality may differ across Europe. The proportion of urban versus rural respondents varied considerably between responding countries. This may reflect differing levels of urbanization in responding countries but may be related to the "snowball" recruitment methods used in some participating countries. We included Kringos classification as a covariate in adjusted analyses, and a sensitivity analysis using country as a covariate did not alter the main results. Respondents practicing in "mixed" geographical settings ( $n=295,14 \%$ of all respondents) were excluded from the analysis. Clinical decision-making comparisons were made using vignettes; while these may not be representative of "real-world" decisions, the vignettes were rigorously developed using evidence-based methodology.[22] Vignettes were used successfully in an earlier study of primary care physicians' behaviour conducted in Nova Scotia Canada, where the stated referral decisions of 225 doctors in response to hypothetical scenarios correlated well with referral data for similar cases obtained from health services and insurance records. [23] Furthermore, a metaanalysis of 111 vignette-based studies demonstrated further close concordance with participants' observed behaviour.[24] The data were collected in 2016 and it is likely that national health systems have continued to evolve in the intervening period, possibly including geographically-focussed restructuring.

\section{Implications}

The finding that rural GPs throughout Europe have less direct access to investigations for patients with suspected cancer is important. Policy-makers need to be able to reduce this disparity if they are to reduce inequalities in the diagnosis of cancer in rural-dwellers. Improving access to medical investigations offers an exciting service design challenge (e.g. point-of-care testing). The finding that rural PCPs perceive greater barriers in terms of travel, cost and provision for their patients highlights that rural European PCPs are key stakeholders in future research and policy to improve outcomes for 
their patients who have cancer. Rural PCPs have experienced and reflected on the challenges faced by their patients and this will be key in informing how to research and improve rural cancer issues. Importantly, rural PCPs appear to be no less likely to make secondary care referrals for patients that might have cancer. This contradicts speculation that rural PCPs are influenced by geography when making cancer diagnostic decisions, a concern that has been widely voiced and perceived as a potential mechanism for rural cancer inequalities. This large and diverse sample provides strong evidence that, when consulted by patients that might have cancer, rural PCPs' investigative instincts and decisionmaking are not blunted by their geographical location. There are dual caveats to interpreting the study. First, there are differing proportions of rural practitioners in the constituent national samples. Second, economic and topographical considerations mean that rurality will likely impact healthcare in different ways in different European countries. Whilst adjustments have been made to account for this in the current analysis, future collaborative research could be mutually instructive to practitioners and policy makers alike by comparing and contrasting the mechanisms by which rurality impacts cancer care across Europe.

\section{Conclusions}

Rural PCPs throughout Europe report poorer access to investigations for potential cancer than Urban PCPs and perceive greater cost, travel and access barriers for their patients. However, rural PCPs across Europe are just as likely to refer or investigate patients that might have cancer at the index consultation as their urban colleagues. 


\section{References}

1. Carriere R, Adam R, Fielding S, Barlas R, Ong Y, Murchie P. Rural dwellers are less likely to survive cancer - An international review and meta-analysis. J Health Place 2018;53:219-227 - doi.org/10.1016/j.healthplace.2018.08.010

2. The World Bank. Rural population (\% of total population) - European Union. https://data.worldbank.org/indicator/SP.RUR.TOTL.ZS?locations=EU\&name desc=fal se [Accessed 14/11/19]

3. Murchie P, Adam R, Wood R, Fielding S. Can we understand and improve poorer cancer survival in rural-dwellers? BJGP Open 2019; DOI: 10.3399/bjgpopen19X101646

4. Bonnett A, Dorsch M, Roder D, Esterman A. Infiltrating ductal carcinoma of the breast in South Australia. Implications of trends in tumour diameter, nodal status and casesurvival rates for cancer control. Med J Aust 1990;152:19-23

5. Campbell NC, Elliott AM, Sharp L, Ritchie LD, Cassidy J, Little J. Rural factors and survival from cancer: analysis of Scottish cancer registrations. Brit J Cancer 2000;82:1863-1866

6. Turner M, Fielding S, Ong Y, Dibben C, Feng Z, Brewster DH, Black C, Lee A, Murchie P. A cancer geography paradox? Poorer cancer outcomes with longer travelling times to healthcare facilities despite prompter diagnosis and treatment: a data-linkage study. Brit J Cancer 2017;117:439-449 - dOI:10.1038/bjc.2017.180

7. Murage $P$, Bachman MO, Crawford SM, McPhail S, Jone A. Geographical access to GPs and modes of cancer diagnosis in England: a cross-sectional study. Fam Pract 2019;36:284-290 - DOI.10.1093/famprac/cmy077

8. Virgilsen LF, Møller H, Vedsted P. Cancer diagnostic delays and travel distance to health services: A nationwide cohort study in Denmark. Cancer Epidemiol 2019;59:115-122. htpps://doi.org/10.1016/j.canep.2019.01.018

9. Virgilsen LF, Møller H, Vedsted P. Travel distance to cancer-diagnostic facilities and tumour stage. Health $\quad$ Place https://doi.org.10.1016/j.healthplace.2019.102208

10. Rubin G, Vedsted P, Emery J. Improving cancer outcomes: better access to diagnostics in primary care could be critical. Brit J Gen Pract 2011;61:317-318

11. Harris M, Taylor G. How health system factors affect primary care practitioners' decisions to refer patients for further investigation: protocol for a pan-European 
ecological study. BMC Health Services Research, 2018;18:338 https://doi.org/10/1186/s12913-018-3170-2

12. Shaghaghi A, Bhopal RS, Sheikh A. Approaches to recruiting "hard-to-reach" populations into research: a review of the literature. Health Promot Perspect 2011;1:86-94

13. Harris $M$, Vedsted $P$, Esteva $M$ et al. Identifying important health system factors that influence primary care practitioners' referrals for cancer suspicion: a European crosssectional survey. BMJ Open 2018:8:e002904. Doi: 10.1136/bmjopen-2018-022904

14. Kringos D, Boerma W, Bourgueil Y, Cartier T, Dedeu T, Hasvold T, Hutchinson A, Lember M, Oleszczyk M, Pavlic DR, Svab I, Tedeschi P, Wilm S, Wilson A, Windak A, Van der Zee J, Groenewegen P. The strength of primary care in Europe: an international comparative study. Br J Gen Pract 2013; DOI: 10.3399/bjgp13X674422

15. Haynes W. (2013) Bonferroni Correction. In: Dubitzky W., Wolkenhauer O., Cho KH., Yokota H. (eds) Encyclopedia of Systems Biology. Springer, New York, NY

16. Kostopoulou O, Nurek M, Cantarella S, Okoli G, Fiorentino F, Delaney B. Referral decision making of General Practitioners: a signal detection study. Med Decis Making 2019;39:21-31. DOI: 10.1177/0272989X18813357

17. Hider P, Lay-Yee R, Davis P. A Comparison of Primary Health Care Provided by Rural and Non-Rural General Practices: The National Primary Medical Care Survey (NatMedCa): 2001/02 Report 4. Ministry of Health, Wellington, New Zealand. 2004. Available from http://www.moh.govt.nz. (Accessed 14/11/2019)

18. Sladden MJ, Thomson AN. How do general practitioners manage rectal bleeding? Aust Fam Physician 1998;27:78-82

19. Haynes RM, Bentham CG. The effects of accessibility on general practitioner consultations, out-patient attendances and inpatient admissions in Norfolk, England. Soc Sci Med 1982;16:561-9

20. Barisic A, Kish M, Gilbert J, Mittmann N, Moineddin R, Sisler J, Vedsted P, Grunfeld E. Family physician access to and wait times for cancer diagnostic investigations Regional differences among 3 provinces. Can Fam Physician 2016, 62;e599-e607

21. Murchie P, Adam R, Khor WL, Raja EA, Iversen L, Brewster DH, Lee AJ. Impact of rurality on processes and outcomes in melanoma care: results from a whole-Scotland 
melanoma cohort in primary and secondary care. Brit J Gen Pract 2018; Aug 2018 e566-e575 - doi.org/10.3399/bjgp18X697901

22. Evans SC, Roberts MC, Keeley JW, Blossom JB, Amaro CM, Garcia AM, Stough CO, Canter KS, Robles R, Reedd GM. Vignette methodologies for studying clinicians' decision-making: Validity, utility, and application in ICD-11 field studies. Int J Clin Health Psychol. 2015;15:160-170. DOI: 10.1016/j.ijchp.2014.12.001

23. Langley GR, Tritchler DL, Llywellyn-Thomas HA, Till JE. Use of written cases to study factors associated with regional variations in referral rates. J Clin Epidemiol 1991;44:391-402. DOI: 10.1016/0895-4356(91)90077-M

24. Murphy K.R., Herr B.M., Lockhart M.C., Maguire E. Evaluating the performance of paper people. J Appl Psychol 1986;71:654-661 


\section{DECLARTION OF INTERESTS}

$P M, W K, R A, M E, E S, D P, H T, P V, D M$ and $M H$ have no competing interests to declare.

\section{ETHICAL APPROVAL}

Consent by the participating PCPs was implied by agreeing to take part in the survey.

Ethical approval for the study has been given by the University of Bath Research Ethics Approval Committee for Health (approval date: 24th November 2014; REACH reference number: EP 14/15 66; UK National Health Service ethical approval is not required). 
Table 1: Description of the 1,779 respondents to European survey on cancer diagnostics - 1238 urban vs 541 rural/is/and primary care physicians

\begin{tabular}{|c|c|c|c|}
\hline & & Urban n (\%) & Rural n (\%) \\
\hline \multirow[t]{5}{*}{ GENDER } & Female & $812(66.0)$ & $282(52.8)$ \\
\hline & Male & $419(34.0)$ & $252(47.2)$ \\
\hline & Not Stated & 7 & 7 \\
\hline & Total & 1238 & 541 \\
\hline & & & $P<0.001^{1}$ \\
\hline \multirow[t]{8}{*}{ YEARS SINCE GRADUATION } & Less than 10 & 220 (17.9) & $47(8.7)$ \\
\hline & 10 to 19 & $315(25.6)$ & $156(29.0)$ \\
\hline & 20 to 29 & $357(29.0)$ & $174(32.3)$ \\
\hline & 30 to 39 & $292(23.7)$ & $142(26.4)$ \\
\hline & 40 or more & $47(3.8)$ & $19(3.5)$ \\
\hline & Prefer not to say & 7 & 3 \\
\hline & Total & 1238 & 541 \\
\hline & & & $P=0.003^{2}$ \\
\hline \multirow[t]{4}{*}{ TRAINED IN GP AND ANOTHER SPECIALTY } & Yes & $93(7.5)$ & $36(6.7)$ \\
\hline & No & $1145(92.5)$ & 505 (93.3) \\
\hline & Total & 1238 & 541 \\
\hline & & & $\mathrm{P}=0.588^{1}$ \\
\hline \multirow[t]{19}{*}{ COUNTRY } & Bulgaria & $44(3.6)$ & $5(0.9)$ \\
\hline & Croatia & $31(2.5)$ & $23(4.3)$ \\
\hline & Denmark & $68(5.5)$ & $14(2.6)$ \\
\hline & England & $28(2.3)$ & $14(2.6)$ \\
\hline & Finland & $56(4.5)$ & $6(1.1)$ \\
\hline & France & $54(4.4)$ & $1(0.2)$ \\
\hline & Germany & $61(4.9)$ & $42(7.8)$ \\
\hline & Greece & $20(1.6)$ & $34(6.3)$ \\
\hline & Israel & $66(5.3)$ & $9(1.7)$ \\
\hline & Italy & $31(2.5)$ & $24(4.4)$ \\
\hline & Netherlands & $55(4.4)$ & $56(10.4)$ \\
\hline & Norway & $50(4.0)$ & $15(2.8)$ \\
\hline & Poland & $108(8.7)$ & $12(2.2)$ \\
\hline & Portugal & $44(3.6)$ & $7(1.3)$ \\
\hline & Romania & $108(8.7)$ & $60(11.1)$ \\
\hline & Scotland & $21(1.7)$ & $19(3.5)$ \\
\hline & Slovenia & $44(3.6)$ & $31(5.7)$ \\
\hline & Spain & $302(24.4)$ & $99(18.3)$ \\
\hline & Sweden & $29(2.3)$ & $25(4.6)$ \\
\hline
\end{tabular}




\begin{tabular}{|llcc|}
\hline & Switzerland & $18(1.5)$ & $45(8.3)$ \\
\hline & Total & 1238 & 541 \\
\hline & & & $\mathbf{P}<\mathbf{0 . 0 0 1}^{3}$ \\
\hline KRINGOS CLASSIFICATION & Strong & $574(46.4)$ & $215(39.7)$ \\
\hline Strength of national primary care system & Medium & $503(40.6)$ & $255(47.1)$ \\
\hline & Weak & $64(5.2)$ & $39(7.2)$ \\
\hline & Unclassified & $97(7.8)$ & $32(5.9)$ \\
\hline & Total & 1238 & 541 \\
\hline & & & $\mathbf{P}=\mathbf{0 . 0 0 7}^{3}$ \\
\hline
\end{tabular}

${ }^{1}$ Chi-squared test with continuity correction

${ }^{2}$ Chi-squared test for trend

${ }^{3}$ Pearson's Chi-squared

Note: Responses of "Prefer not to say" and "Not stated" were excluded from statistical analysis 
Table 2: Direct access to investigations by urban vs rural primary care physicians in European survey on cancer diagnostics

\begin{tabular}{|c|c|c|c|c|}
\hline & Direct access available to PCP & Urban & Rural & P value $^{1}$ \\
\hline \multirow[t]{2}{*}{ ULTRASOUND } & Yes & $1176(95.0)$ & $480(88.7)$ & \\
\hline & No & $62(5.0)$ & $61(11.3)$ & $P<0.001^{1}$ \\
\hline \multirow[t]{2}{*}{ ENDOSCOPY } & Yes & $923(74.6)$ & $312(57.7)$ & \\
\hline & No & $315(25.4)$ & $229(42.3)$ & $P<0.001^{1}$ \\
\hline \multirow[t]{2}{*}{ X-RAY } & Yes & 1175 (94.9) & $482(89.1)$ & \\
\hline & No & $63(5.1)$ & 59 (10.9) & $P<0.001^{1}$ \\
\hline \multirow[t]{2}{*}{ ADVANCED SCANNING } & Yes & $825(66.6)$ & $279(51.6)$ & \\
\hline & No & $413(33.4)$ & $675(48.4)$ & $P<0.001^{1}$ \\
\hline
\end{tabular}

${ }^{1}$ Chi-squared test with continuity correction 
TABLE 3: Comparison of rural and urban PCPs' stated diagnostic actions (investigation or referral) at index consultation for each of the four clinical vignettes

\begin{tabular}{|c|c|c|c|c|c|}
\hline & & Action taken $\mathrm{n}(\%)$ & No action taken $\mathrm{n}(\%)$ & Unadjusted OR (95\% Cl) rural vs urban & Adjusted OR $(95 \% \mathrm{Cl})$ rural vs urban ${ }^{1}$ \\
\hline \multirow[t]{2}{*}{ Lung Cancer } & Urban & $682(55.1)$ & $556(44.9)$ & & \\
\hline & Rural & $301(55.6)$ & $240(44.4)$ & $1.02(0.83-1.25)$ & $0.90(0.72-1.12)^{1}$ \\
\hline \multirow[t]{2}{*}{ Ovarian Cancer } & Urban & $689(55.7)$ & $549(44.3)$ & & \\
\hline & Rural & $319(59.0$ & $222(41.0)$ & $1.15(0.93-1.41)$ & $0.95(0.75-1.19)^{1}$ \\
\hline \multirow[t]{2}{*}{ Breast Cancer } & Urban & 725 (58.6) & $513(41.4)$ & & \\
\hline & Rural & $318(58.8)$ & $223(41.2)$ & $1.01(0.82-1.24)$ & $0.87(0.70-1.09)^{1}$ \\
\hline \multirow[t]{2}{*}{ Colorectal Cancer } & Urban & 980 (79.2) & $258(20.8)$ & & \\
\hline & Rural & $431(79.7)$ & $110(20.3)$ & $1.03(0.80-1.33)$ & $0.98(0.75-1.30)^{1}$ \\
\hline
\end{tabular}

${ }^{1}$ Adjusted for gender, years since graduation, Kringos classification, direct access to relevant investigations

TABLE 4 : Specialist referral made by those taking diagnostic action at index consultation for each of the four clinical vignettes (rural vs urban) including unadjusted and adjusted odds that diagnostic action at index consultation is specialist referral (rural vs urban)

\begin{tabular}{|llccc|}
\hline & & $\begin{array}{c}\text { Referred to a specialist } \\
\mathbf{n}(\%)\end{array}$ & $\begin{array}{c}\text { Not referred } \\
\mathbf{n}(\%)\end{array}$ & $\begin{array}{c}\text { Unadjusted OR (95\% Cl) } \\
\text { rural vs urban }\end{array}$ \\
\hline Lung Cancer ( $\mathbf{n = 9 8 3 )}$ & Urban & $151(22.1)$ & $531(77.9)$ & $1.23(0.90-1.69)$ \\
\hline & Rural & $78(25.9)$ & $222(74.0)$ & \\
\hline Ovarian Cancer (n=1008) & Urban & $280(40.6)$ & $409(59.4)$ & $0.84(0.64-1.10)$ \\
\hline & Rural & $116(36.4)$ & $203(63.6)$ & $1.12(0.75-1.68)^{1}$ \\
\hline Breast Cancer (n=1043) & Urban & $513(70.8)$ & $212(29.2)$ & \\
\hline & Rural & $225(70.8)$ & $93(29.2)$ & $0.71(0.51-0.99)^{1}$ \\
\hline Colorectal Cancer (n=1411) & Urban & $700(71.4)$ & $280(28.6)$ & $0.75-1.34)$ \\
\hline & Rural & $340(78.9)$ & $91(21.1)$ & $1.50(1.14-1.96)$ \\
\hline
\end{tabular}

${ }^{1}$ Adjusted for gender, years since graduation, Kringos classification, direct access to relevant investigations 
TABLE 5: Comparing rural and urban PCPs attitudes to health service factors affecting diagnosis of cancer in primary care (3-point Likert scale)

\begin{tabular}{|c|c|c|c|c|c|}
\hline & & DISAGREE & $\begin{array}{c}\text { NEITHER AGREE OR } \\
\text { DISAGREE }\end{array}$ & AGREE & P value ${ }^{1,2}$ \\
\hline \multirow[t]{2}{*}{ I am able to refer to a specialist that I know personally } & URBAN n (\%) & $416(39.0)$ & $172(16.1)$ & 480 (44.9) & $P=0.001^{1,2}$ \\
\hline & RURAL n (\%) & $142(30.0)$ & $85(18.0)$ & $246(52.0)$ & \\
\hline \multirow[t]{2}{*}{ Here specialists usually welcome referrals } & URBAN n (\%) & 293 (27.2) & $343(31.8)$ & $441(40.9)$ & $\mathrm{P}=0.001^{1,2}$ \\
\hline & RURAL n (\%) & $101(21.4)$ & $136(28.8)$ & $235(49.8)$ & \\
\hline \multirow[t]{2}{*}{ I can easily telephone a specialist for informal discussion } & URBAN n (\%) & $303(28.4)$ & 204 (19.1) & $559(52.4)$ & $P=0.020^{1,2}$ \\
\hline & RURAL n (\%) & $116(24.5)$ & 75 (15.9) & $282(59.6)$ & \\
\hline \multirow[t]{2}{*}{ I am able to refer directly to a named specialist } & URBAN n (\%) & $291(27.0)$ & $96(8.9)$ & $690(64.1)$ & $\mathrm{P}=0.522^{1,2}$ \\
\hline & RURAL n (\%) & $113(24.0)$ & 56 (11.9) & $302(64.1)$ & \\
\hline \multirow[t]{2}{*}{ My colleagues criticise me if I have referred a patient } & URBAN n (\%) & 631 (58.6) & $227(21.1)$ & $218(20.3)$ & $\mathrm{P}=0.532^{1,2}$ \\
\hline & RURAL n (\%) & $273(57.8)$ & 94 (19.9) & $105(22.2)$ & \\
\hline \multirow{2}{*}{ Seeing a specialist can be costly for patients } & URBAN n (\%) & $620(57.8)$ & $123(11.5)$ & $330(30.8)$ & $P<0.001^{1,2}$ \\
\hline & RURAL n (\%) & $194(41.4)$ & 56 (11.9) & $219(46.7)$ & \\
\hline \multirow[t]{2}{*}{ We have access to a fast-track specialist appointment system } & URBAN n (\%) & $238(22.1)$ & $93(8.6)$ & $746(69.3)$ & $P=0.006^{1,2}$ \\
\hline & RURAL n (\%) & $129(27.3)$ & $53(11.2)$ & $291(61.5)$ & \\
\hline \multirow[t]{2}{*}{ We have a budget or quota for diagnostic tests } & URBAN n (\%) & $573(53.6)$ & $171(16.0)$ & $325(30.4)$ & $P=0.176^{1,2}$ \\
\hline & RURAL n (\%) & 266 (57.1) & 73 (15.7) & $127(27.3)$ & \\
\hline \multirow[t]{2}{*}{ Referral costs are usually paid by insurance companies } & URBAN n (\%) & $620(58.5)$ & 140 (13.2) & $300(28.3)$ & $P<0.001^{1,2}$ \\
\hline & RURAL n (\%) & $216(46.3)$ & $58(12.4)$ & $193(41.3)$ & \\
\hline \multirow[t]{2}{*}{ Patients can self-refer to specialists } & URBAN n (\%) & $841(78.5)$ & $105(9.8)$ & $125(11.7)$ & $P=0.002^{1,2}$ \\
\hline & RURAL n (\%) & 331 (70.1) & 69 (14.6) & $72(15.3)$ & \\
\hline \multirow[t]{2}{*}{ In my practice patients often have to travel a long way } & URBAN n (\%) & $866(81.5)$ & $95(8.9)$ & $101(9.5)$ & $P<0.001^{1,2}$ \\
\hline & RURAL n (\%) & $230(49.1)$ & 65 (13.9) & $173(37.0)$ & \\
\hline \multirow[t]{2}{*}{ I am very busy and sometimes refer to help reduce my work } & URBAN n (\%) & $632(58.9)$ & $200(18.6)$ & $241(22.5)$ & $P<0.001^{1,2}$ \\
\hline & RURAL n (\%) & $328(69.6)$ & $79(16.8)$ & $64(13.6)$ & \\
\hline \multirow[t]{2}{*}{ I am likely to refer if a patient requests referral } & URBAN n (\%) & 357 (33.2) & $267(24.8)$ & $451(42.0)$ & $P=0.736^{1,2}$ \\
\hline & RURAL n (\%) & $148(31.2)$ & $145(30.5)$ & $182(38.3)$ & \\
\hline \multirow[t]{2}{*}{ We are under media or public pressure to refer earlier } & URBAN n (\%) & $343(31.8)$ & $242(22.5)$ & $492(45.7)$ & $P=0.308^{1,2}$ \\
\hline & RURAL n (\%) & $138(29.0)$ & $111(23.3)$ & $227(47.7)$ & \\
\hline \multirow[t]{2}{*}{ The local health system encourages us to refer any patients } & URBAN n (\%) & $330(30.7)$ & $272(25.3)$ & $472(43.9)$ & $\mathrm{P}=0.011^{1,2}$ \\
\hline & RURAL n (\%) & $121(25.6)$ & $111(23.5)$ & $240(50.8)$ & \\
\hline \multirow[t]{2}{*}{ I usually have time in the consultation to think carefully } & URBAN n (\%) & $334(31.0)$ & 214 (19.9) & $529(49.1)$ & $\mathrm{P}=0.008^{1,2}$ \\
\hline & RURAL n (\%) & $116(24.5)$ & $96(20.3)$ & $262(55.3)$ & \\
\hline \multirow[t]{2}{*}{ Common presentations are covered by local or national guidelines } & URBAN n (\%) & $145(13.5)$ & $242(22.5)$ & $688(64.0)$ & $\mathrm{P}=0.785^{1,2}$ \\
\hline & RURAL n (\%) & 65 (13.9) & 96 (20.6) & $306(65.5)$ & \\
\hline In general patients prefer a GP to look after them & URBAN n (\%) & $222(20.5)$ & $424(39.2)$ & $435(40.2)$ & $\mathrm{P}=0.003^{1,2}$ \\
\hline
\end{tabular}




\begin{tabular}{|c|c|c|c|c|c|}
\hline & RURAL n (\%) & $69(14.6)$ & $184(38.9)$ & $220(46.5)$ & \\
\hline \multirow[t]{2}{*}{ Here high quality care for patient more important than costs } & URBAN n (\%) & $152(14.2)$ & $211(19.7)$ & 709 (66.1) & $\mathrm{P}=0.632^{1,2}$ \\
\hline & RURAL n (\%) & $78(16.5)$ & $80(16.9)$ & $314(66.5)$ & \\
\hline \multirow[t]{2}{*}{ Referring or not referring doesn't affect me financially } & URBAN n (\%) & $158(14.8)$ & $136(12.7)$ & $776(72.5)$ & $\mathrm{P}=0.404^{1,2}$ \\
\hline & RURAL n (\%) & $60(12.8)$ & $62(13.2)$ & $346(73.9)$ & \\
\hline
\end{tabular}

${ }^{1}$ P-value from the Chi-squared test for trend with Bonferroni correction applied (accepted level of significance is $p=0.05 / 20$ ( $p=0.0025$ )

SUPPLEMENTARY TABLE: Comparison of rural and urban PCPs' stated diagnostic actions (investigation or referral) and likelihood of referral at index consultation for those intending action for each of the four clinical vignettes - adjusted for country rather than Kringos classification

\begin{tabular}{|ccc|}
\hline & $\begin{array}{c}\text { Adjusted OR for diagnostic action taken } \\
(\mathbf{9 5 \%} \mathrm{Cl}) \text { rural vs urban }\end{array}$ & $\begin{array}{c}\text { Adjusted OR for specialist referral } \\
(\mathbf{9 5 \%} \mathrm{Cl}) \text { urban vs rural }^{\mathbf{1}}\end{array}$ \\
\hline & $0.91(0.72-1.15)^{1}$ & $1.46(0.92-2.31)^{1}$ \\
\hline Lung Cancer & $0.95(0.74-1.21)^{1}$ & $0.94(0.66-1.35)^{1}$ \\
\hline Ovarian Cancer & & $0.75(0.52-1.08)^{1}$ \\
\hline Breast Cancer & $1.06(0.83-1.35)^{1}$ & \\
\hline & & $1.41(1.02-1.96)^{1}$ \\
\hline Colorectal Cancer & $0.79(0.59-1.05)^{1}$ & \\
\hline
\end{tabular}

${ }^{1}$ Adjusted for gender, years since graduation, country, direct access to relevant investigations 